\title{
Sobre gênero neutro em português brasileiro e os limites do sistema linguístico
}

\author{
Luiz Carlos SCHWINDT (1) \\ Universidade Federal do Rio Grande do Sul (UFRGS)
}

○

OPEN ACCESS

EDITADO POR

- Raquel Freitag (UFS)

AVALIADO POR

- Danniel Carvalho (UFBA)

- Maria Carlota Rosa (UFRJ)

DATAS

- Recebido: 08/10/2020

- Aceito: 09/11/2020

- Publicado: 17/11/2020

COMO CITAR

Schwindt, L. C. (2020)

Sobre gênero neutro em português brasileiro e os limites do sistema linguístico. Revista da Abralin, v. 19, n. 1, p. 1-23, 2020.

\section{RESUMO}

Neste texto, proponho uma abordagem de neutralização de gênero em português brasileiro na perspectiva do sistema linguístico. Para isso, parto de considerações sobre a caracterização de mudanças deliberadas e sobre os padrões de marcação e produtividade de gênero gramatical na língua. São avaliados, nessa perspectiva, quatro tipos de empregos correntes de gênero inclusivo: uso de feminino marcado no caso de substantivos comuns de dois gêneros (ex. a presidenta); emprego de formas femininas e masculinas, sobretudo em vocativos, em vez do uso genérico do masculino (ex. alunas e alunos); inclusão de novas marcas no final de nomes e adjetivos, como x e @ (ex. amigx, amig@), ou ampliação da função de marcas já existentes, como -e (ex. amigue); alteração na base de pronomes e artigos (ex. ile, le). Desses empregos, além do feminino marcado e do contraste entre formas femininas e masculinas, que já têm uso significativo na língua, proponho que, no domínio da palavra, -e encontra condições menos limitadas para expansão no sistema no subconjunto de substantivos e adjetivos sexuados.

\section{ABSTRACT}

In this paper, I propose an approach to gender neutrality in Brazilian Portuguese from the perspective of the linguistic system. For this, I start from considerations about the characteristics of deliberate changes and the patterns of markedness and productivity of the grammatical gender in the language. In this perspective, four types of current uses of inclusive gender are evaluated: marked feminine in case of two genders nouns (eg. a 


\section{REVISTA DA ABRALIN}

presidenta 'the president', feminine); contrastive and concurrent feminine and masculine forms, especially in vocatives, instead of the generic use of masculine (eg alunas e alunos, 'students', feminine and masculine); special characters closing nouns and adjectives, such as x and @ (eg amigx, amig@, 'friend', neuter), or extension of the function of existing marks, such as -e (eg amigue 'friend', neuter); change in the base of pronouns and articles (eg ile '3rd sing neutral pronoun', le 'definite neutral article'). Among these forms, in addition to the marked feminine and the contrastive use of feminine and masculine forms, which already have significant use in the language, I propose that, in the domain of the word, -e finds less restricted conditions for expansion in the system considering the subset of nouns and adjectives denoting biological sex.

PALAVRAS-CHAVE

Gênero neutro. Gênero gramatical. Mudança deliberada. Linguagem inclusiva.

KEYWORDS

Gender neutrality. Grammatical gender. Deliberate change. Inclusive language.

\section{Introdução}

O debate pela inclusão de grupos pertencentes a gêneros em alguma medida marginalizados na esfera social atingiu de cheio a linguagem, em diferentes países, de modo especial na última década. Em português brasileiro (PB), isso repercutiu em propostas/usos como os exemplificados em (1), que contemplam, respectivamente: o uso marcadamente feminino de nomes comuns de dois gêneros; o emprego de formas femininas e masculinas, sobretudo em vocativos e pronomes, em vez do uso genérico do masculino; a inclusão de novas marcas no final de nomes e adjetivos, como x e @; a ampliação da função de marcas já existentes, como $e$; alterações na base ou raiz de pronomes e artigos.

(1) a. presidenta

b. alunas e alunos, todas e todos

c. amigx, amig@, amigue

d. ile, nile, dile, aquile, le...

Embora nem todos os exemplos em (1) se caracterizem como estratégias de neutralização, dialogam com essa noção, muitas vezes trivializada. À linguística deve interessar um entendimento claro 


\section{REVISTA DA ABRALIN}

sobre neutralização enquanto expediente formal das línguas naturais. Neste texto, proponho, à luz desse entendimento, uma reflexão sobre as estruturas em (1), algumas já caracterizadas em dada medida no uso, outras ainda figurando como propostas para o uso inclusivo da linguagem.

Convidado a co-organizar um painel no evento ABRALIN AO VIVO sobre uso inclusivo de gênero e a proferir uma palestra sobre tema análogo no evento CONVERSA COM O GEFONO, e tendo realizado pesquisa sobre produtividade de marcadores gramaticais de gênero nos últimos 4 anos, identifiquei a demanda de pensar sobre as restrições de natureza fonológica e morfológica envolvidas na instanciação de um suposto gênero neutro em português, objeto central deste artigo. ${ }^{1}$ A ideia foi produzir um material capaz de informar inclusive não linguistas, ainda que atenda o pedido direto de colegas linguistas, que, confrontados com o tema no seu fazer diário, identificaram a necessidade de um texto que adotasse os graus de tecnicalidade e de simplificação que tento equilibrar aqui.

Não está em primeiro plano aqui o debate sobre o caráter sexista de línguas como o português ou qualquer outra, ainda que este seja tema de reconhecida relevância. Com isso não se assume que marcas linguísticas não possam refletir preconceitos de ordem diversa. Trata-se, a rigor, tão somente de recorte, que se justifica pela perspectiva teórico-analítica que assumo no artigo.

O texto se organiza como segue. Na seção 1, trago uma reflexão breve sobre o que se entende por sistema ou gramática em línguas naturais, partindo do Curso de Linguística Geral e, para além dele, contemplando a dinamicidade da mudança. Na seção 2 , em posse de uma tentativa de conceptualização de gênero enquanto categoria gramatical, descrevo alguns dos principais indicadores de produtividade de marcadores de gênero no PB. Essas duas seções subsidiam a reflexão sobre os limites para a instanciação de gênero neutro em PB, realizada na seção 3. Na seção 4, apresento uma breve síntese das principais ideias desenvolvidas no texto e algumas considerações finais.

\section{A noção de sistema e os limites da mudança linguística}

Qualquer linguista, ao falar pela primeira vez sobre a ciência para alguém, precisa explicar pelo menos duas coisas: que línguas naturais não são objetos caóticos e que não prescrevemos comportamentos linguísticos. Se isso é bem assimilado, falamos, então, de regras ou restrições sem medo de

\footnotetext{
${ }^{1}$ O evento ABRALIN AO VIVO é iniciativa da Associação Brasileira de Linguística em cooperação com diferentes associações nacionais e internacionais da área. A referida mesa realizou-se no dia 14/7/2020, 19h, e foi organizada em parceria com as professoras Raquel Meister Ko. Freitag e Ana Paula Rabelo. CONVERSA COM O GEFONO é um evento promovido pelo Grupo de Pesquisa em Fonologia da Universidade Federal de Uberlândia, coordenado pelo Prof. José Magalhães. Minha participação aconteceu em 24/9/2020, às $14 \mathrm{~h}$.
} 


\section{REVISTA DA ABRALIN}

sermos confundidos com moralistas da linguagem. Nos termos da linguística formal, tratamos, neste caso, de sistema, ou de gramática, sem o pejo do arbítrio. ${ }^{2}$

O Curso de Linguística Geral (CLG), obra inaugural da Linguística Moderna, publicado em 1916, de autoria atribuída a Ferdinand de Saussure, assume a noção de sistema para definir o objeto da linguística. A língua, opondo-se à fala, é eleita o objeto estrito dessa ciência. Homogênea, psíquica e coletiva, a língua opera com unidades que, complementares, distinguem-se, levando em conta sons mentais e sentido. Valor, então, nessa concepção, depende de distintividade. Exemplificando no contexto do fenômeno abordado aqui, podemos dizer que um falante de português atribui valor de feminino a nomes sexuados terminados na vogal $a$, como menina, em contraste à sua ausência, em menino, que tem valor oposto, de masculino. Saussure assume o signo como a principal entidade de análise e o observa numa perspectiva fonocêntrica. Por desejar focar gênero como categoria morfofonológica, essa também é a abordagem predominante neste texto, ainda que exemplos envolvendo formas escritas e estruturas maiores do que a palavra sejam explorados na medida de sua relação com o recorte assumido.

Uma das propriedades desse controverso objeto estabelecido pelo CLG define-se por um suposto paradoxo: o signo linguístico é, a um tempo, imutável e mutável. Enquanto herança, a língua limita sincronicamente o falante, é uma carta forçada. Por outro lado, a força social combinada aos efeitos do tempo é capaz de deslocar as relações entre as unidades pré-estabelecidas nos sistemas, resultando em mudança, perceptível, contudo, do ponto de vista da língua apenas diacronicamente.

A visão estática de mudança linguística preconizada pelo CLG é redimensionada a partir dos achados da sociolinguística variacionista. Labov (1966), ao propor que a mudança pode ser captada em tempo aparente, a partir do exame dos fatores que concorrem para a variação na sincronia das línguas, em particular a variável idade, consolida um olhar dinâmico sobre o fenômeno.

A questão sobre como uma mudança se implementa é complexa e extrapola os objetivos deste artigo. Para discutir, porém, a possível reestruturação do PB para comportar a marcação neutra de gênero, é inevitável que reflitamos pelo menos sobre a maior ou menor necessidade de consciência dos falantes para que uma mudança tome lugar. Labov propôs uma distinção, de base psicológica e social, entre mudanças vindas de cima, as que se processam acima do nível da consciência e são introduzidas pela classe dominante, e mudanças vindas de baixo, as que se processam abaixo do nível da consciência e têm origem no vernáculo. Segundo Guy (2011), essa distinção é insuficiente, se considerarmos que há mudanças que, apesar de espontâneas, são conscientes, e outras que, mesmo refletindo acomodação a um modelo externo, podem se processar inconscientemente. Também contraditando a dicotomia laboviana, Thomason (2007) defende que não apenas mudanças inconscientes mas também mudanças deliberadas podem ser entendidas como naturais e atingir de modo permanente uma comunidade de fala.

\footnotetext{
${ }^{2}$ O termo formal aqui é usado na perspectiva ampla da distinção saussuriana forma vs. substância. Inscreve-se sob esse rótulo também a teoria gerativa, com a oposição competência vs. performance, mas também outras teorias que concebam algum nível de modularidade linguística, estabelecida por grau de abstração.
} 


\section{REVISTA DA ABRALIN}

Assumindo-se, então, o pressuposto de que, sim, o sistema pode se sujeitar a mudanças demandadas conscientemente pelos falantes, como uma que alterasse a morfologia de gênero do PB, o questionamento se situa no seu grau de espontaneidade e de naturalidade - critérios igualmente não dispensados por uma mudança deliberada.

A noção de espontaneidade não é de fácil caracterização em Linguística. Nos dias atuais, no caso específico de uma mudança envolvendo marcas inclusivas de gênero, esses usos podem facilmente se disseminar por redes sociais, blogs e outros expedientes virtuais, em grande parte na modalidade escrita.

O exame da densidade de uso de formas inovadoras em postagens de redes sociais, por exemplo, é um expediente que pode contribuir para a compreensão do grau de espontaneidade na propagação de uma mudança deliberada. Nesse sentido, realizei, apenas como exercício, uma busca no Twitter, das formas amiga, amigo, amigue e amigx, usando a Plataforma R, em particular o pacote TwitteR. Dadas as limitações da versão de desenvolvedor utilizada, a busca se limitou a 18.000 ocorrências, compreendendo o período de 18 a 27 de setembro. O gráfico a seguir mostra, à esquerda, a densidade total de cada forma e, à direita, a comparação entre a densidade de tweets e retweets.
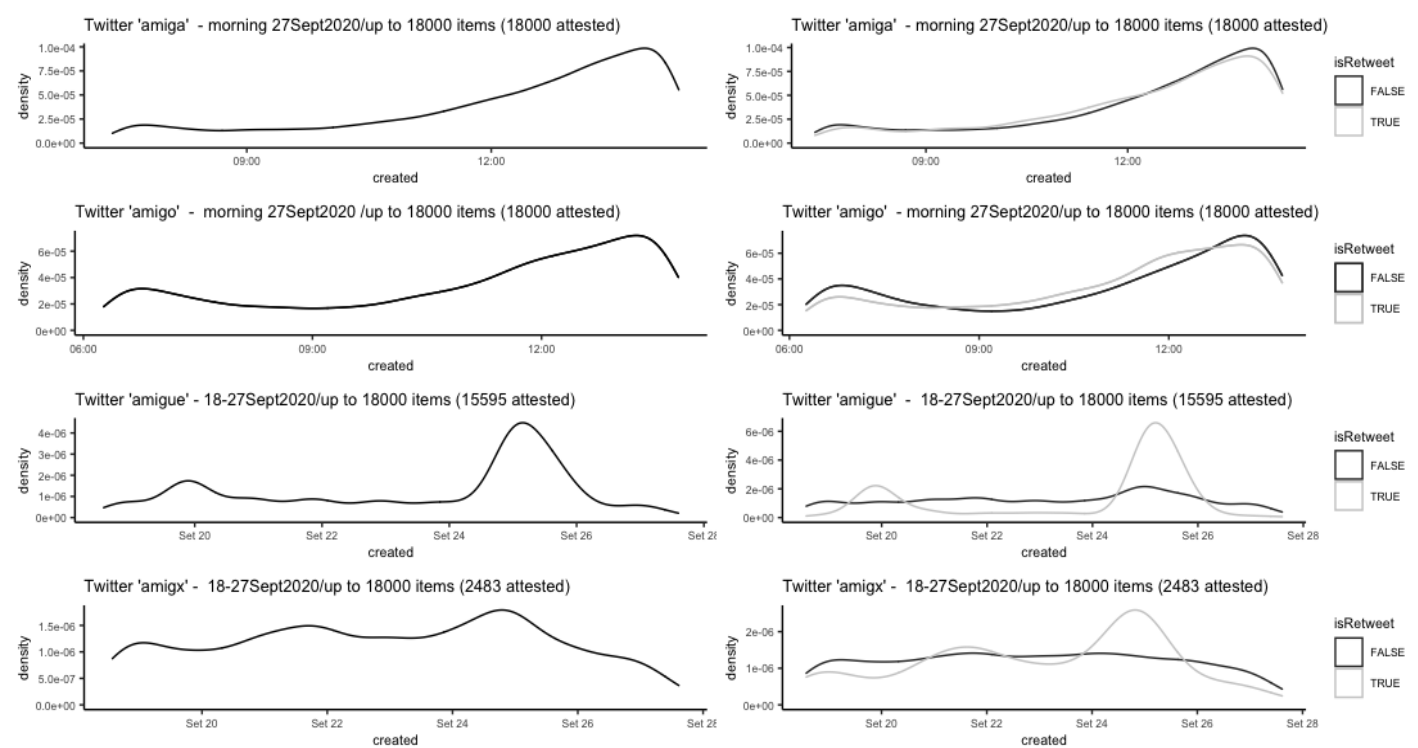

FIGURA 1 - Densidade de tweetse retweets amiga, amigo, amigue, amigx Fonte: Elaborado pelo autor.

Destaco a seguir alguns aspectos relevantes dos resultados deste exercício. Em relação às alternantes padrão, amigas e amigos, observa-se pequena diferença de frequência em favor da forma feminina, que alcança o limite máximo de 18.000 ocorrências em $6 \mathrm{~h}$ e $57 \mathrm{~min}$, em contraste com a masculina, que alcança esse limite em 7 h e 32min. A distribuição da densidade de amiga é também muito semelhante à de amigo. Retweets, como mostram os gráficos à direita, acompanham a curva dos tweets, sem indício de que atuem como impulsionadores do uso dessas variantes neste recorte de dados. Em relação às variantes inovadoras, amigue supera com larga vantagem a frequência de amigx, a primeira forma alcançando 15.595 ocorrências contra 2.483 da segunda em 10 dias. Para as 


\section{REVISTA DA ABRALIN}

duas variantes observa-se um pico de densidade entre os dias 24 e 26 de setembro, que pode ter sido impulsionado por retweets. Esse resultado, pela evidente limitação do exercício, não é suficiente para se duvidar do caráter espontâneo de uma possível mudança no sentido de inclusão de uma marca de gênero neutro em $\mathrm{PB}$, mas serve à reflexão sobre o papel dos formadores de opinião na propagação de uma mudança dessa natureza. Nesse quesito, uma questão que foge ao foco deste artigo, mas que é relevante, diz respeito à estratificação social de quem introduz e carreia uma mudança desse tipo, já que a ideia de classe dominante, sugerida por Labov como propriedade de mudanças vindas de cima, não parece caracterizar irrestritamente os grupos que não se sentem incluídos em termos de gênero no Brasil. Se insistíssemos em manter esse pressuposto, contudo, poderíamos considerar a hipótese de que o movimento talvez se dê, a rigor, a partir de uma classe intelectualmente dominante, possivelmente apenas parcialmente isomórfica com a que se pretende efetivamente incluir. Como não quantificamos essa informação, contudo, essa hipótese figura aqui tão somente como especulação.

Naturalidade, o segundo critério que mencionei como essencial para que uma mudança consciente se processe, e que tomo como central neste debate, também é noção sujeita a alguma controvérsia em Linguística. Nesta abordagem, que situei de partida na esfera do formalismo, porém, o entendimento é mais ou menos tácito. Naturalidade é conceito que sofistica o pressuposto de simplicidade de regras ou restrições fonológicas acrescentando-lhe a expectativa de plausibilidade fonética (HYMAN, 1975). Atestável de modo geral por meio da comparação de processos entre diferentes línguas, muitas vezes com base no que tradicionalmente se rotula como universais linguísticos, naturalidade é aspecto que também pode ser avaliado no interior de um sistema, considerandose a preservação de contrastes e a relação entre regras/restrições ativas nos diversos subsistemas.

No que diz respeito às propostas para neutralização de gênero em PB, uma recomendação envolvendo o plural de substantivos que circula em diversos meios é particularmente ilustrativa em relação à necessidade da inclusão do parâmetro de naturalidade na avaliação do fenômeno. O exemplo, extraído do site medium.com, em matéria de autoria de Ophelia Cassiano, intitulada Guia para 'Linguagem Neutra' (PT-BR), diz respeito a uma alternativa de neutralização de nomes terminados em res no masculino e ras no feminino, como professores/professoras. ${ }^{3}$

(2) Realizaram uma homenagem aes professories.

A sugestão de adoção da sequência final ries ao nome visa a distingui-la do plural do masculino, professores. Meu entendimento é de que esta regra é pouco natural, nos termos aqui definidos, no sistema do PB. O fato é que, apesar de o português contar com um conjunto restrito de vocábulos, todos femininos, terminados na sequência rie átona - a saber, cárie, série, barbárie, intempérie, superfície -, está sujeito nesses casos a um processo de redução ou monotongação,

\footnotetext{
${ }^{3}$ No texto em questão, a autora rotula a cadeia segmental rie como desinência de gênero. Intencionalmente ou não, a classificação conduz à tese de morfologização dessa estrutura segmental (e, por paralelismo de res e ras). Essa análise, entretanto, falha no mínimo pelo fato de / $/$, neste caso, ser parte da raiz das palavras a que se aplicam essas formas de plural.
} 


\section{REVISTA DA ABRALIN}

extensivo ao plural, resultando em formas como cár[I], sér[I], barbár[I], intempér[I], superfíc[I]. Uma possível motivação para essa redução pode ser a evitação ao hiato, [ri.e], ou, no caso de reparado o hiato por ditongação, a evitação a sequências de segmentos homorgânicos, [.rji]. Não há evidência para se supor que tal redução isentaria formas inovadoras com semelhante estrutura fonológica. Isso ocorrendo, o plural do masculino e o plural do aventado neutro se tornariam idênticos, professor[I]s. Alguém poderia, todavia, contraditar afirmando que homofonia é um fenômeno comum na superfície fonética das línguas, incluindo o português. A pergunta, porém, seria por que uma língua introduziria uma oposição de caráter consciente num sistema para que ela fosse desfeita por restrições de caráter inconsciente ativas no mesmo sistema. ${ }^{4}$ Redução em posições fracas, e particularmente em final de palavra, assim como suas possíveis motivações - evitação a hiato ou a sequências homorgânicas -, são restrições ativas em muitas línguas do mundo, razão por que devem ser consideradas na avaliação de naturalidade de um fenômeno como o que analisamos. Essa tese é retomada mais adiante, na seção 3, quando problematizo a naturalidade de algumas das propostas para marcação neutra de gênero em substantivos do PB, levando em conta restrições de base fonológica, morfológica, sintática e semântica.

\section{Produtividade de gênero em PB}

Um pressuposto para se discutir mudança num sistema de marcação de gênero é o entendimento sobre a natureza e a extensão dessa categoria no subsistema morfológico das línguas do mundo e, aqui, de modo particular, do português.

Não há uma definição universal para a categoria gênero em estudos gramaticais. A definição proposta por Hocket (1958, p. 231), contudo, segundo a qual "gêneros são classes de nomes refletidas no comportamento de palavras associadas", é suficiente para a abordagem que apresento neste texto. Isso porque, desfazendo-se, de partida, a hipótese de isomorfismo perfeito entre gênero e sexo, talvez seja mais fácil se entender inclusive essa relação na superfície das línguas. ${ }^{5}$ Gênero, assim, numa perspectiva geral poderia ser representado por algarismos ou letras ou poderia até mesmo ser rebatizado como

\footnotetext{
${ }^{4}$ Este tipo de operação, que cria uma estrutura para desfazê-la na mesma derivação ou vice-versa, é conhecido como Duke of York Gambit, termo cunhado pelo linguista inglês-americano Geoffrey Pullum, em analogia a uma cantiga inglesa tradicional contendo os seguintes versos: The Grand Old Duke of York / He had ten thousand men / He marched them up a great high hill / And he marched them down again.

${ }^{5}$ Esse conflito, aliás, segundo Bonazzi (2020), já estaria presente na reflexão de Protágoras (séc. V a.C.), a quem Aristóteles confere o crédito de ter sido o primeiro a distinguir o gênero de nomes (masculino, feminino e neutro) e também a propor correções de uso baseadas tanto em forma quanto em significado. Nesse sentido, teria sugerido que nomes fechados por sigma ou que designassem noções do mundo masculino, como $\mu \tilde{\eta} v \iota \varsigma$ "ira, furor" ou $\pi \eta^{\prime} \lambda \eta \xi$ "capacete" (termos relacionados à guerra, uma carreira eminentemente masculina à época), não fossem femininos.
} 


\section{REVISTA DA ABRALIN}

classe, salvaguardada a ambiguidade deste termo com outras categorias gramaticais vigentes na descrição linguística (como classe temática ou classe de palavra, por exemplo).

De acordo com Corbett (1991), embora recorrente nas línguas do mundo, nem todos os idiomas codificam gênero. Nos sistemas que concebem essa categoria é frequente se identificar alguma correspondência semântica com sexo biológico, como é o caso das línguas indoeuropeias, ainda que este não seja um fato universal. Traços como [ \pm animado], [ \pm racional], $[ \pm$ humano], [ \pm forte], entre outros, podem também embasar sistemas de gênero. E mesmo os sistemas baseados em sexo podem se diferenciar importantemente quanto ao número de categorias adotadas e suas combinações com outros traços semânticos e propriedades formais.

O português está entre os sistemas híbridos na atribuição de gênero: o traço [ \pm sexuado], relevante para um subconjunto restrito de nomes (ex. menina vs. menino; gerente vs. gerenta), está combinado às propriedades fonológicas e sintáticas que exponenciam gênero e classe temática em todos os nomes na língua. De modo simples: as vogais -a, -o e -e estão presentes também em palavras que não estabelecem qualquer relação com sexo (ex. bola; bolo; ponte; pente) e nuclearizam a concordância na frase nos mesmos moldes dos vocábulos sexuados, conforme (3).
(3) a. a menina alta
d. o menino alto
b. a bola preta
e. o bolo saboroso
c. a ponte torta
f. o pente largo

Essa distribuição levou Camara Jr. (1970), no espírito de oposições privativas, a considerar o feminino, instanciado por -a, a forma marcada de gênero nos nomes sexuados, em oposição à sua ausência, caracterizadora do masculino. As vogais finais nos demais vocábulos marcam classe temática, segundo o autor, a despeito de seu gênero. Segundo essa abordagem, podemos afirmar que gênero em português é expresso fonologicamente em um número consideravelmente reduzido de substantivos.

Não é tácito que a categoria gênero constitua uma marca propriamente flexional dos substantivos em português, por conta de sua impredizibilidade lexical, como afirma Villalva (2008). Em outras palavras, não podemos prever, em princípio, o valor de masculino e feminino para uma mesma raiz como prevemos, por exemplo, o número (já que qualquer raiz nominal só pode se realizar no singular ou no plural em nossa língua). ${ }^{6}$ Além disso, o fato de encontrarmos palavras masculinas e femininas terminadas nos mesmos fonemas contribui para o diagnóstico de impredizibilidade.

Apesar, contudo, do inegável caráter idiossincrático da categoria, falantes de português tendem a acertar com considerável acurácia o gênero de novas palavras da língua, baseados em aspectos semânticos e/ou formais. Isso se observa, por exemplo, diante de vocábulos emprestados: enquanto paper é masculino para a maioria dos falantes, mídia é feminina. No primeiro caso, por exemplo, pode-se aventar analogia com um vocábulo como artigo, ao passo que, no segundo, a vogal final pode ser responsável

\footnotetext{
${ }^{6}$ Nos adjetivos e determinantes do português, contudo, gênero é produto de concordância, o que lhe assegura predizibilidade neste caso.
} 


\section{REVISTA DA ABRALIN}

pela definição do gênero. A hipótese que defendo é a de que o conhecimento sobre o sistema de marcação e sobre a produtividade de estruturas linguísticas responde por essa predizibilidade de gênero atestada na prática (SCHWINDT, 2020). Marcação e produtividade são, nessa perspectiva, parte do conhecimento linguístico internalizado pelos falantes nativos de uma língua. ${ }^{7}$ No que concerne ao sistema de marcação, trata-se, em português, do domínio das oposições asseguradas pelos segmentos fonológicos, ou por sua ausência, na porção final do tema. No que respeita à produtividade, refere-se ao domínio da frequência de tipo e de ocorrência das palavras - e também de estruturas menores do que ela, como morfemas, sílabas e fonemas. Isso provavelmente explica por que falantes de PB consideram uma forma como o atleta natural, mas o crianço estranha ao sistema.

Sustento que o sistema de marcação de gênero do português respeita uma hierarquia de realização de morfemas abstratos limitada por restrições fonológicas (SCHWINDT, 2011; 2018). Entre essas restrições fonológicas está uma bastante geral, que demanda que nomes sejam preferencialmente fechados por vogais átonas (92\%, em levantamento no Dicionário Aurélio Eletrônico, descrito em maior detalhe adiante). Esse fato, tomado independentemente, já serve para repensar o pressuposto de amálgama necessário entre essas vogais e morfemas, como queriam os distribucionalistas norte-americanos. Isso é tão verdadeiro que, quase categoricamente, inserimos uma vogal epentética em siglas e palavras estrangeiras fechadas por obstruintes, como MEC[I], rap[I], Tick[I] Tok[I], sem que atribuamos valor semântico a esses sons. Subordinada à restrição que privilegia palavras fechadas por vogal, há outra que limita essas vogais átonas a apenas 3, /i,u,a/, como resultado de neutralização nessa posição. Morfemas abstratos, então, como FEminino e MASculino, que são categoricamente atribuídos a todos os nomes portugueses, se realizarão a depender dessa disponibilidade segmental, garantidos contrastes. Palavras terminadas por consoante ou por vogal tônica, como mar e café, em princípio não realizam foneticamente gênero, apesar de contarem com essa categoria em sua matriz morfossintática. Palavras terminadas em vogal átona podem ou não realizar gênero foneticamente em português, sendo o único contraste mais ou menos tácito aquele descrito por Camara Jr., segundo o qual -a se associa a formas femininas em oposição à ausência dessa marca (ex. gerenta vs. gerente; menina vs. menino). Formas não femininas são entendidas nessa perspectiva como não marcadas, no sentido de que não são associadas a um expoente distintivo. O fato, então, de formas masculinas atuarem como genéricas (um termo mais adequado do que neutras neste caso) é compreendido como decorrência desse sistema de marcação.

O sistema de marcação, entretanto, não se mostra suficiente para explicar a intuição dos falantes sobre a atribuição de gênero em uma língua como o português. Parece que nosso conhecimento internalizado da língua inclui também informação sobre a produtividade das formas e das restrições envolvidas no processo. Trata-se, neste recorte do termo, de um conhecimento de natureza quantitativa, em última instância: alimentados pelo input que recebemos, temos um juízo em geral acertado sobre o que é mais frequente ou menos frequente na língua. A seguir listo três generalizações

\footnotetext{
${ }^{7}$ Se assumirmos que produtividade é noção que se divide em disponibilidade e rentabilidade, como propõe Corbin (1987), podemos dizer que, em dada medida, o conhecimento internalizado sobre o sistema de marcação é também medida de produtividade, uma vez que nos permite predizer as formas que podem ser disponibilizadas na língua.
} 


\section{REVISTA DA ABRALIN}

que refletem em certa medida o senso comum sobre representação de gênero em nomes do PB acompanhadas de seu falseamento baseado em informações sobre produtividade. Os dados que alimentam essa reflexão são substantivos extraídos de duas fontes: 17.049 types do Dicionário Aurélio Eletrônico e 4.800 tokens de 24 entrevistas relativas às capitais que integram o Projeto Variação Linguística na Região Sul do Brasil (VARSUL). Os resultados estão disponíveis com maior detalhamento em Schwindt (2018; 2020).

\subsection{Primeira generalização: há mais substantivos masculinos do que femininos}

Em termos absolutos, essa generalização não se confirma nem nos dados do dicionário nem nos dados de uso. Se considerados todos os substantivos, a língua é bastante equilibrada em termos de distribuição de palavras femininas e masculinas, com leve vantagem para as femininas. Observado, porém, o subgrupo dos itens sexuados sujeitos a variação de gênero, que representa 5,6\% dos nomes dicionarizados, essa realidade se inverte, com clara prevalência de masculino tanto entre biformes quanto entre comuns de dois. Considerando-se a saliência sociocognitiva desse grupo, podemos supor que se localize aí a principal razão para a impressão de maior contingente de nomes masculinos na língua.

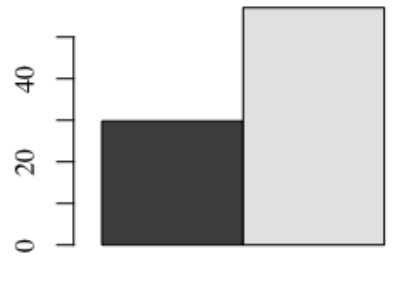

biform

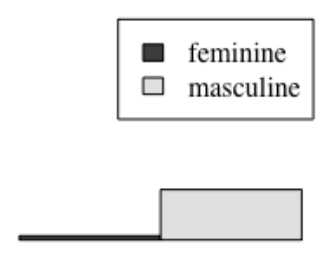

two gender

FIGURA 2 - Gênero de nomes sexuados em PB - VARSUL

Fonte: Elaborado pelo autor.

\subsection{Segunda generalização: palavras femininas terminam em -a, palavras masculinas} terminam em -o e vice-versa

Essa generalização tem grande respaldo quantitativo, ainda que não apresente simetria absoluta, já que há palavras fechadas por -a no léxico do português que podem eventualmente ser masculinas. Isso se confirma no uso. 


\section{REVISTA DA ABRALIN}

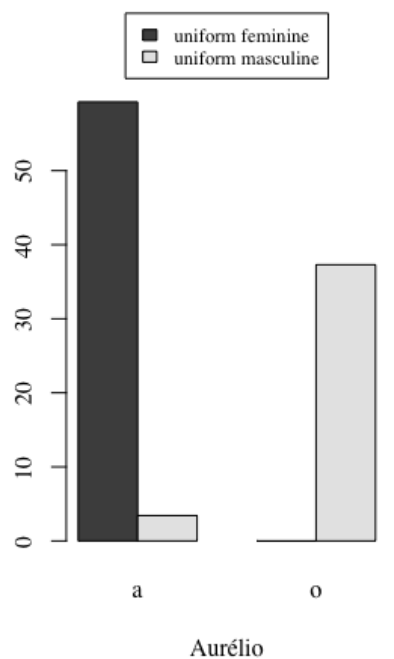

FIGURA 3 - Gênero e vogais -a e -o - Dicionário Aurélio e VARSUL

Fonte: Elaborado pelo autor.

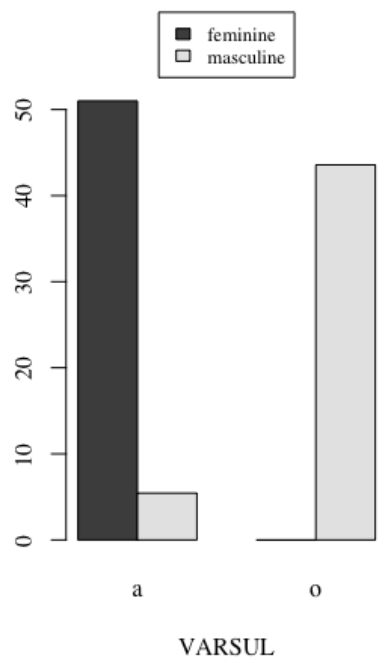

O PB não possui substantivos genuinamente femininos terminados em -o, à exceção do vocábulo tribo. Os dicionários listam também imago, virago e libido, os dois primeiros termos pouco ou não empregados no Brasil e o último muitas vezes se realizando no masculino. Menos incomum são formas deadjetivais femininas fechadas em -o, parafraseáveis com uma estrutura como do tipo X, como é o caso de soprano: ela é uma soprano / ela é uma cantora do tipo soprano. Palavras masculinas fechadas por -a, por outro lado, são frequentes na língua, tanto em substantivos uniformes quanto comuns de dois gêneros, inclusive entre nomes sexuados (ex. o amálgama, o atleta).

\subsection{Terceira generalização: palavras terminadas em -e são comuns de dois gêneros}

Substantivos terminados em -e podem se referir a todos os tipos de gêneros de palavras portuguesas: uniforme feminino (ex. ponte), uniforme masculino (ex. pente), comum de dois (ex. o/a presidente) e ainda biforme masculino (na oposição o presidente / a presidenta). Entre as formas dicionarizadas, na amostra geral, como se observa no gráfico a seguir, apenas $4,6 \%$ são substantivos comuns de dois gêneros. A maioria dos nomes, 94,4\%, é feminina ou masculina, com alguma vantagem das primeiras, e 1\% é de palavras biformes que se flexionam com marcas alternativas (ex. embaixatriz, abadessa, princesa). A amostra dos nomes sexuados, contudo, mais uma vez justifica a intuição de parte dos falantes. Neste subgrupo, o índice de substantivos comuns de dois gêneros sobe para $72,6 \%$, caracterizando-se como categoria predominante. 


\section{REVISTA DA ABRALIN}

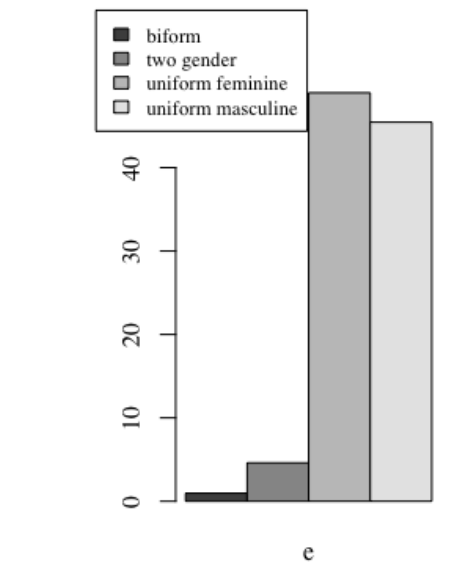

Geral - Aurélio

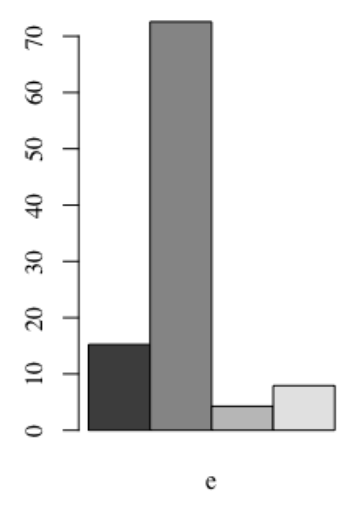

Sexuados - Aurélio

FIGURA 4 - Tipologia de gênero e vogal -e - geral e sexuados - Dicionário Aurélio Fonte: Elaborado pelo autor.

Parte do entendimento de que -e é um bom marcador de neutro em PB provém possivelmente também do comportamento dos nomes no subgrupo dos sexuados. Na amostra de uso, os nomes sexuados em -e apresentam comportamento mais ou menos equilibrado, com alguma vantagem para o masculino, 57,6\% (o que pode não ser exatamente um favorecedor da disseminação de -e como marca de neutro).

O exercício em torno dessas generalizações contribui para refletir sobre a extensão do que se rotula como conhecimento linguístico em perspectivas formalistas, o que inclui, entre muitas outras variáveis, informações sobre sistemas de marcação e sobre produtividade de formas linguísticas. Toda mudança, para que alcance a coletividade, está submetida a esse conhecimento. Nesse sentido, a ideia é de que não há mudança irrefreável, como inadvertidamente alguém poderia supor. Enquanto processo, qualquer mudança pode ser impulsionada ou freada por variáveis de natureza linguística, como as que abordo neste artigo, ou sociais.

\section{Gênero neutro e os limites do sistema}

Nesta seção, a partir da exploração conceitual do termo neutralização em gramática, exploro algumas possibilidades de neutralização de gênero em PB.

Neutralização, no sentido da Escola de Praga, envolve cancelamento de um contraste, isto é, tem lugar quando duas ou mais entidades opostas deixam de se diferenciar. As vogais [o] e [o] em português, em posição pretônica, não diferenciam palavras quanto ao significado. Portanto, não há, 


\section{REVISTA DA ABRALIN}

em princípio, que se atribuir valor gramatical a essa distinção no sistema. ${ }^{8}$ Disso decorre o contexto para que se neutralizem. A neutralização, nesse caso, pode se instanciar em pelo menos três caminhos, segundo Trubetzkoy (1939): a coexistência dos dois sons, a adoção de um dos dois sons pelo par em neutralização ou o emprego de um novo som, representativo dos dois. Esse entendimento de neutralização, assim concebido para a fonologia, pode, mutatis mutandis, ser considerado na análise de fenômenos morfofonológicos.

O português, apesar de não ter herdado o neutro latino, prevê algumas possibilidades de uso genérico por meio do masculino, uma forma já existente no sistema. ${ }^{9}$ É, por exemplo, o caso do emprego do masculino plural em português ou de formas coletivas do masculino singular, como nas construções em (4).

(4) a. Professores terão prioridade na vacinação.

b. Amigo de verdade nunca te abandona.

Essa possível neutralização, contudo, se dá apenas em nível semântico, pois, como antecipei, o processo de concordância sempre revela o gênero dos supostos neutros, como se vê em (5).

(5) a. Professores aposentados terão prioridade na vacinação.

b. Amigo sincero de verdade nunca te abandona.

Nem todas as propostas relativas ao uso inclusivo de gênero dizem respeito a neutralização e nem todas as que almejam neutralização estão se referindo ao tipo que acabo de descrever. Recupero os exemplos de (1) para propor uma reflexão sobre quatro tipos de emprego inclusivo de gênero e relaciono esses usos a possíveis abordagens de neutralização.

\subsection{A presidenta}

Motivo de intensa e injustificada polêmica no governo Dilma Rousseff, o uso marcado do feminino de substantivos tradicionalmente empregados como comuns de dois gêneros é exemplo indispensável ao debate acadêmico e político sobre a relação entre a construção de identidades de gênero e

\footnotetext{
${ }^{8}$ Isso não quer dizer que tal distinção é irrelevante para o estudo da língua. Muito pelo contrário: sabemos que a distinção de abertura entre vogais médias pretônicas pode contribuir para se identificar, por exemplo, o falar de um gaúcho em contraste ao de um baiano, quando pronunciam uma palavra como coração - o que sinaliza para valor linguístico, ainda que em outra base.

${ }^{9}$ Observe-se que mesmo palavras empregadas na forma latina original de nominativo neutro, como forum, são definidas binariamente quanto ao gênero gramatical em português.
} 


\section{REVISTA DA ABRALIN}

usos linguísticos com foco no feminino, como o promovido por Freitag e Severo (2015). O exemplo não caracteriza evidentemente um caso de neutralização, mas sua análise pode contribuir para a reflexão sobre o fenômeno. Pelo contrário, aqui a marcação reforça um contraste binário e privativo de gênero do português (sem o qual muito provavelmente o objetivo de inclusão não seria alcançado). Este caso, aliás, analisado da perspectiva de sua terminação, é mais uma das importantes evidências sobre os limites do sistema na instanciação de marcas de gênero. Por que parece haver diferentes graus de estranheza para falantes nativos em relação a termos como presidenta, estudanta e contribuinta? Uma das razões é a natureza híbrida do sufixo -nte, resquício do particípio presente latino que sobrevive no português como morfema derivacional responsável por formar nomes a partir de verbos. A hipótese que defendo, na linha do que propõem Gonçalves e Silva (2020), é de que palavras fechadas pelo sufixo -nte em português possuem diferentes graus de autonomia em relação aos verbos de que derivam, uma espécie de memória não assimilada plenamente pela categorização de que dispomos sincronicamente, que acaba por justificar uma interpretação fluida da relação flexão/derivação. Nesse sentido, nomes como presidenta, por seu maior distanciamento do verbo presidir, têm rápida assimilação pelo sistema; no outro extremo parece estar contribuinta, e formas como estudanta se situariam no meio desse espectro. ${ }^{10}$ Para além, portanto, das questões ideológicas que certamente são responsáveis por nomes de muitas profissões e cargos fechados por -nte serem predominantemente masculinos, há questões estruturais que podem representar resistência à velocidade da mudança neste caso.

Por outro lado, a língua registra exemplos de feminino empregado como neutro. São casos que merecem especial atenção por soarem cada vez mais naturais para falantes nativos de PB veiculando os significados que procuro representar pelas etiquetas subscritas em (6).

(6) a. Professores e professoras $_{\mathrm{ii}}$ queridas $\mathrm{i}_{\mathrm{i}, \mathrm{i}}$, parabéns pelo seu dia!

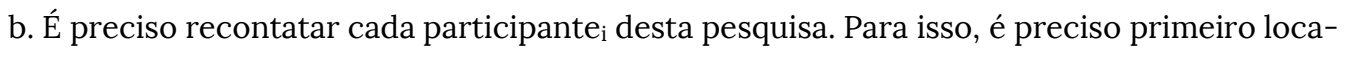
lizá-las.

c. Minhas melhores amigas $\mathrm{i}=\mathrm{a}+\mathrm{b}$ são mulheres $\mathrm{b}$.

Em (6a) vemos um caso bastante recorrente atualmente. Ao se enunciarem em especial em vocativos, as formas de masculino e feminino, nesta ordem, a concordância com o adjetivo que segue o par de substantivos, assumindo o valor do termo adjacente, neste caso o feminino, mantém referência com os dois nomes que o precedem, frustrando a expectativa de exclusividade do masculino genérico. (6b), um exemplo que adaptei de um texto acadêmico, ilustra um caso de recuperação pronominal no feminino de um substantivo masculino empregado genericamente para homens e

\footnotetext{
${ }^{10}$ Note-se que em formas não sufixadas terminadas nessa mesma sequência fonológica, como gigante ou elefante, a forma marcada de feminino (giganta, elefanta) parece soar mais natural de modo geral.
} 


\section{REVISTA DA ABRALIN}

mulheres. ${ }^{11}$ (6c), frase enunciada por um artista numa entrevista de televisão, revela um caso mais complexo: o gênero gramatical do conjunto maior, que, para fazer sentido, precisa incluir homens e mulheres, é determinado pelo subconjunto feminino.

\subsection{Alunas e alunos; todas e todos}

Cada vez mais recorrente, o emprego de formas femininas e masculinas em vez do uso genérico também não se classifica como um expediente de neutralização. Trata-se, ao contrário, como no caso de presidenta, da afirmação da binariedade no sistema de gênero, neste caso numa oposição equipolente, ou seja, duplamente marcada. Embora mais recorrente em vocativos, recuperando uma fórmula antiga do português e de outras línguas presente em expressões cristalizadas (ex. senhoras e senhores; ladies and gentlemen), este uso se estende atualmente, por vezes, a todos os elementos do sintagma.

(7) Caras alunas e caros alunos, pedimos a todas e todos que estejam interessadas/interessados em certificado que registrem seu pedido no primeiro dia do evento.

A frase (7) não apresenta qualquer inovação em relação à estrutura gramatical canônica do português. Apesar de computacionalmente viável, esse tipo de construção pode encontrar alguma limitação pragmática, sobretudo na fala, que tende a ser mais econômica do que a escrita por razões possivelmente relacionadas a memória. Violar, contudo, o pressuposto de economia, combinado ao ordenamento do feminino antes do masculino, parece ser justamente o que está em jogo para se alcançar o objetivo de inclusão nesse uso.

\subsection{Amigx, amig@, amigue}

O uso de caracteres como x ou @ e o uso de $e$ fechando substantivos e adjetivos é de fato uma estratégia de neutralização de gênero, em que se propõe o emprego de uma terceira marca além da masculina e da feminina. A oposição neste caso não seria privativa nem equipolente, mas gradual, nos termos da Escola de Praga. ${ }^{12}$

\footnotetext{
${ }^{11} \mathrm{O}$ exemplo (6b) se aproxima do efeito obtido pelo uso contemporâneo do que se rotula como they singular em inglês, que se aplica a pessoas que não se identificam com o masculino ou o feminino: This is my friend, Jay. I met them at work. They are a talented artist.

${ }^{12}$ Os tipos de oposição sustentados por Trubetzkoy aplicam-se particularmente a traços fonológicos, o que dificulta um pareamento perfeito com propriedades morfológicas em certo aspecto. Assim, se classificamos como gradual uma tipologia tripartite de gênero,
} 


\section{REVISTA DA ABRALIN}

O emprego, para fins de neutralização, de x e @, contudo, se diferencia importantemente do emprego de -e, pelo fato de os primeiros só se aplicarem à escrita (embora @ lembre visualmente $a$ ), uma vez que esses caracteres não encontram correspondência conhecida no sistema fonológico do português. Esse argumento, aliás, passou recentemente a figurar em muitas recomendações sobre uso inclusivo de gênero, que orientam hoje que se evitem tais formas, por não poderem ser processadas plenamente por leitores automáticos, o que exclui pessoas privadas de visão. O problema, porém, é mais complexo. Não se pode ignorar que o sistema alfabético, embora seja em muitos aspectos independente da língua oral, tem sua base tanto filogenética quanto ontogenética na oralidade. Dada a natureza dinâmica da fala em contraste com a estaticidade da escrita, o resultado é um sistema com correspondências imperfeitas. A maior parte das imperfeições provém de estipulações, determinadas muitas vezes por mera herança histórica, regimentadas por acordos ortográficos e vocabulários oficiais, por conveniências muitas vezes extralinguísticas. Determinar que letras não correspondem a sons numa língua, portanto, é, em minha compreensão, contraintuitivo do ponto de vista científico. Seria como propor às avessas a convenção que tirou o trema das sequências gu/qu pronunciadas em linguiça, mas não em enguiça.

O uso de -e, pronunciado em geral como [I], como marcador de neutro tem maior motivação no interior da língua, seja por se conformar ao inventário fonológico, seja por já possuir papel morfológico, figurando como marcador de classe temática. Todavia, este último fato, como mostrei na descrição do comportamento de $e$ realizada na seção 2, pode exercer algum controle sobre a progressão de uma mudança nesse sentido, já que, como vimos, há palavras masculinas e femininas fechadas por essa vogal na língua. Entretanto, no grupo dos nomes sexuados que fazem oposição a/o, como vimos, uma forma de neutro em -e parece encontrar algum lugar. Por outro lado, não se pode perder de vista que a inclusão de um -e designando neutro nesse grupo força a identificação de -a e -o como marcas respectivas de feminino e masculino, ou seja, demandando, ao menos formalmente, uma oposição do tipo presidenta vs. presidento vs. presidente. O prejuízo é que o emprego de formas como presidenta reduzem neste caso seu potencial pragmático de inclusão, que parece mais efetivo num contraste binário.

Duas questões que se impõem à formação de neutro tanto com caracteres como x e @ quanto com -e são a definição da referência semântica e a determinação ou indeterminação por artigos e pronomes, bem como a retomada pronominal. O problema da referência semântica é esperado neste tipo de mudança, em que se tem mais de uma possível entidade passível de ser representada: uma marca genérica para masculino e feminino, como se ilustra a seguir em (8a), ou uma marca designando um terceiro gênero, como se ilustra em (8b).

(8) a. Amigues querides, eu uso e porque não quero excluir ninguém.

b. Bom dia amigas, amigos e amigues!

por exemplo, não resta clara uma justificativa para se definirem os extremos de uma suposta escala, já que categorias como masculino-neutro-feminino não parecem se desenhar claramente em um contínuo. 


\section{REVISTA DA ABRALIN}

O problema da determinação por artigos e pronomes e da retomada pronominal, ilustrado em (9), a seguir, revela que gênero é mais do que uma informação lexical: trata-se de um mecanismo gramatical de que se vale o sistema por razões de economia.

(9) Meus(?) dois(?) amigues mais próximes, Vini e Léo, chegaram. Preciso dar atenção a eles(?).

$3.4 \|$ lle, nile, dile, aquile, le...

Para confrontar o problema ilustrado em (9) é que surgem propostas mais complexas de marcação neutra de gênero na língua, até aqui de uso ainda restrito, envolvendo artigos e pronomes. Há várias alternativas nesse sentido, algumas mais sofisticadas estruturalmente do que outras, intituladas em geral de sistemas. Abordo como ilustração apenas uma aqui, e de forma simplificada, habitualmente referida como "Sistema Ile", recentemente bastante difundida a partir do vídeo de rosalaura_, divulgado em seu perfil do Instagram em 6 de setembro de 2020. ${ }^{13}$ Outras informações sobre esse e outros sistemas estão disponíveis especialmente na internet, em blogs, redes sociais e inclusive em textos colaborativos como a Wikipédia. Nessa proposta, o que se sugere é incrementar o sistema morfológico com novos morfemas ou com alomorfes de morfemas já existentes.

(10) Ile se lembrou de sue prime e daquile amigue da escola.

Basicamente dois expedientes formais estão em jogo: acréscimo de -e fechando as estruturas e alguma modificação na base (ou raiz) desses morfemas. No caso do artigo neutro, por exemplo, sugere-se a criação de um novo morfema, $l e$, opondo-se a $a$ e $o$. A inserção de um $l$ antes de $e$ serviria para diferenciar essa forma da partícula ou conjunção aditiva. A escolha de uma lateral alveolar neste caso parece se basear na expressão dos pronomes oblíquos lo/la, ainda que essas formas, que só acontecem em contexto de ênclise, sejam produto histórico da fonotaxe entre marca de infinitivo, $r$, com os pronomes o/a (ex. encontrar + a = encontrá-la). No caso do pronome de terceira pessoa, propõe-se uma forma inovadora que se assemelha a formas já existentes na língua, ela/ele, o que sugere que se trata de alomorfia da raiz. Emprega-se $i$ no lugar de $e$, em ile, possivelmente com base

\footnotetext{
${ }^{13}$ Nessa perspectiva, destaco estudo de Carvalho e Silva (2019), que propõe um levantamento de textos coletados em redes sociais e letras de músicas populares com o emprego do pronome êla em PB, complementado por uma consulta sobre a impressão de usuários do Facebook acerca desse uso.
} 


\section{REVISTA DA ABRALIN}

na alternância presente em este/esta/isto/aquele/aquela/aquilo. ${ }^{14}$ Aqui, o custo é de se depender de duas informações morfológicas num mesmo vocábulo: o acréscimo do morfema -e na borda direita da palavra, e a alternância na vogal da base. Há casos semelhantes na morfologia do português, como a metafonia da vogal da raiz em formas femininas ou pluralizadas (ex. n[o]va / [0]lhos). A diferença neste caso é que a informação morfológica, ainda que também veiculada pela abertura da vogal, não é dependente dessa informação. A proposta atinge outras formas pronominais, com comportamento semelhante aos exemplos descritos. Destaco os pronomes possessivos minhe/tue/sue. O possessivo de $1^{\text {a }}$ pessoa assume a alomorfia da forma feminina, minha, com acréscimo de -e, minhe. Proposta concorrente sugere a forma mi, semelhante à de pronome análogo em espanhol. No caso dos possessivos de $2^{\mathrm{a}}$ e $3^{\mathrm{a}}$ pessoa, cria-se um hiato, que, prosperando, em decorrência da redução da átona final possivelmente se ditongaria na maioria dos dialetos: $t[u j], s[u j]$.

Diferente das outras alternativas de inclusão que problematizei até aqui, esses usos exigem aprendizagem formal em alguma medida. Como qualquer aprendizagem linguística, pode ser facilitada a depender de seu grau de naturalidade.

\section{Considerações finais}

Neste texto, partindo da noção de sistema linguístico e de fatos sobre a produtividade no uso de marcadores de gênero em português brasileiro, procurei refletir sobre empregos inclusivos de linguagem neutra.

Alguns aspectos de caráter geral devem ser considerados numa mudança consciente, ou deliberada, envolvendo a morfologia de uma língua. O primeiro deles é que, apesar de o fenômeno da variação e da mudança atingir os diferentes níveis da linguagem, não os atinge em igual escala. Pelo modo como os sistemas linguísticos se organizam, e não por questões sincronicamente ideológicas, primitivos, como morfemas, fonemas e condições de estrutura silábica, são mais resistentes a mudanças. Ser resistente, porém, não significa ser impermeável. O grau de permeabilidade, contudo, parece depender da pressão dos fatores sociais e da naturalidade dos processos envolvidos na mudança, estes últimos a que me referi como limites do sistema. O segundo aspecto que destaco é que um movimento deliberado de mudança no sistema gramatical depende de clareza coletiva sobre o referente semântico das formas inovadoras e da consciência de que, seja qual for esse referente, sua representação formal será sempre um recorte categorial. Desse modo, é preciso que as pessoas conheçam e sejam capazes de identificar no mundo, de forma mais ou menos tácita, o significado de

\footnotetext{
${ }^{14}$ As formas isto/aquilo, a propósito, ilustram um caso particular de neutro semântico do português, no sentido de designarem seres inanimados. São formas masculinas, que têm comportamento sintático distinto das formas este/esta, já que, ao contrário dessas, não precedem substantivos na frase.
} 


\section{REVISTA DA ABRALIN}

categorias como cis, trans, não binário etc. para que as marcas linguísticas que as designem se estabeleçam no uso. Mesmo assim, uma gramática que conte apenas com o/a/e designando, respectivamente, masculino, feminino e não binário, ainda que amplie as possibilidades de representação linguística de entidades do mundo, seguirá não dando conta de todas as possíveis segmentações ou subsegmentações de gênero social.

Alguns dos empregos inclusivos de gênero que considerei neste texto encontram-se em pleno uso na língua, como a marcação feminina de nomes comuns de dois gêneros e a adoção concomitante de formas femininas e masculinas, sobretudo em vocativos e pronomes, em lugar do uso genérico do masculino. Tais empregos se classificam melhor, eu diria, como uso neutro de gênero do que exatamente como uso de gênero neutro. Outros empregos têm uso mais restrito, alguns ainda figurando como propostas, como é o caso do Sistema Ile e de outros esquemas envolvendo pronomes. Os segmentos finais x e @, que apresentaram alguma aplicação para marcar neutro nos nomes até mesmo em usos menos informais nos últimos anos, vêm se tornando mais escassos por serem restritos à escrita, já que o sistema ortográfico do português não prevê correspondência para esses caracteres no sistema fonológico, particularmente em núcleo de sílaba. Em dada medida, parece prosperar, em contrapartida, o emprego de -e como morfema alternativo de neutro em substantivos e adjetivos que se referem a seres sexuados. O ritmo, porém, de uma variação e possível mudança nesse sentido em PB é controlado pelo sistema de marcação e pela produtividade de palavras fechadas por esta vogal. A ambiguidade de um neutro em -e com usos masculinos de nomes fechados por essa mesma vogal (ex. o presidente) exemplifica essa complexidade.

Entre os muitos papéis da Linguística, seguramente está o de entender como a mudança se processa com olhar especializado, seja interno ou externo ao que chamei aqui de sistema. Sendo ciência, embora não lhe caiba qualquer tipo de prescrição sobre condutas verbais, tem compromisso inegociável com o entendimento das diferenças. Nesse sentido, o já significativo conjunto de estudos sobre uso inclusivo e marcação neutra de gênero em PB, ao qual se soma este ensaio, pode oferecer importante contribuição.

\section{Agradecimentos}

Agradeço ao Conselho Nacional de Desenvolvimento Científico e Tecnológico, à Fundação de Amparo à Pesquisa do Estado do Rio Grande do Sul e à Pró-Reitoria de Pesquisa da Universidade Federal do Rio Grande do Sul pelo fomento em diferentes etapas da pesquisa em que se enquadra este ensaio teórico. Agradeço também aos leitores atentos deste texto, os pareceristas Maria Carlota Rosa e Danniel da Silva Carvalho e os estudantes Pedro Perini Surreaux, Rossana Saute Kolodny e Pedro Eugênio Gaggiola, pelos valiosos comentários e sugestões para aprimoramento de sua versão final, cujos equívocos residuais são de minha responsabilidade pessoal. 


\section{REVISTA DA ABRALIN}

\section{REFERÊNCIAS}

BONAZZI, M. Protagoras. In: ZALTA, E. N. (ed.) The Stanford Encyclopedia of Philosophy, Fall 2020 Edition. Disponível em:

https://plato.stanford.edu/archives/fall2020/entries/protagoras/. Acessado em 2/11/2020.

CAMARA JR., J. M. Estrutura da língua portuguesa. Petrópolis, RJ: Vozes, 1970. 114p.

CARVALHO, D.; SILVA, I. J. Êla é muito cobiçado: um pronome neutro que não o é. Colóquio do Museu Pedagógico, v. 13, n.1, 2019, p. 1074-1078.

CORBETT, G. Gender. Cambridge: Cambridge University Press, 1991. 363p.

CORBIN, D. Morphologie dérivationnelle et structuration du lexique. Tübingen: Max Niemeyer Verlag, 1987. 940p.

FREITAG, R. M. K..; SEVERO, C. G. (org.) Mulheres, linguagem e poder: estudos de gênero na sociolinguística brasileira. São Paulo: Blucher, 2015. 304p.

GONÇALVES, C. A.; SILVA, J. C. T. Sobre o estatuto de -nte: evidência de um continuum flexão-derivação para a mudança morfológica do latim ao português. Labor Histórico, Rio de Janeiro, v. 6, n.1, p. 57-83, 2020. DOI: https://doi.org/10.24206/lh.v6i1.30736

GUY, G. Variation and Change. In: MAGUIRE, W.; MCMAHON, A. (Ed). Analyzing variation in English. Cambridge: Cambridge University Press, 2011. p. 178-198.

HOCKETT, C. F. A course in modern linguistics. New York: Macmillan, 1958. 621p.

HYMAN, L. M. Phonology: theory and analysis. New York: Holt, Rinehart \& Winston, 1975. 268p.

LABOV, W. The social stratification of English in New York City. Washington, D. C.: Center for Applied Linguistics, 1966. p. 655

SAUSSURE, F. Curso de Linguística Geral. São Paulo: Cultrix, [1916](1988). 279p.

SCHWINDT, L. C. Zeros na morfologia nominal portuguesa à luz da Optimal Interleaving Theory. ReVEL, v. 9, n. 5 , 2011. Disponível em:

http://www.revel.inf.br/files/artigos/revel_esp_5_zeros_na_morfologia.pdf

SCHWINDT, L.C. Exponência de gênero e classe temática em português. DELTA, São Paulo, v. 2, n. 34, p. 745-768, 2018. DOI http://dx.doi.org/10.1590/0102-44509154975775546

SCHWINDT, L. C. Predizibilidade da marcação de gênero em substantivos no português brasileiro. In: CARVALHO, D.; BRITO, D. (Org.). Gênero e língua(gem): formas e usos. 1ed. Salvador: Editora da UFBA, 2020. p. 279-294. Disponível em:

https://www.researchgate.net/publication/339339566 Genero e linguagem formas e usos

THOMASON, S. Language Contact and Deliberate Change. Journal of Language Contact, v. 1, n. 1, p.41-62, 2007. DOI https://doi.org/10.1163/000000007792548387

TRUBETZKOY, N. S. Principles of Phonology. Traduzido do alemão por Christiane A. M. Baltaxe. Berkeley and Los Angeles: University of California Press, [1939]1969. p.344

VILLALVA, A. Morfologia do português. Lisboa: Universidade Aberta, 2008. p.170. 


\section{REVISTA DA ABRALIN}

\section{PARECER DE MARIA CARLOTA ROSA NO ARTIGO "SOBRE GÊNERO NEUTRO EM PORTUGUÊS}

BRASILEIRO E OS LIMITES DO SISTEMA LINGUÍSTICO"

DOI 10.25189/rabralin.v19i1.17091

\section{Visão geral}

O ensaio retoma o debate sobre o gênero em português. Diferentemente dos muitos trabalhos sobre o tema, o A. discute a introdução recente no português do Brasil de formas que se constituem em reflexos linguísticos intencionais de uma atitude social inclusiva. Assim, o A. focaliza "quatro tipos de empregos correntes de gênero inclusivo: uso de feminino marcado no caso de substantivos comuns de dois gêneros (ex. a presidenta); emprego de formas femininas e masculinas, sobretudo em vocativos, em vez do uso genérico do masculino (ex. alunas e alunos); inclusão de novas marcas no final de nomes e adjetivos, como x e @ (ex.amigx, amig@), ou ampliação da função de marcas já existentes, como -e (ex. amigue); alteração na base ou raiz de pronomes e artigos (ex. ile, le)". Os dois primeiros tipos já têm uso corrente no Brasil. Os dois últimos são a parte instigante do ensaio.

\section{Comentários}

\subsection{Importância}

O A. justifica a escolha do tema, que focaliza um fenômeno recente no português do Brasil. Chama a atenção para a repercussão que o tema começa a ter, com a criação de verbetes na Wikipedia e em sites de não linguistas, o que chama os linguistas para a discussão.

\subsection{A descrição}

O ensaio compreende cinco partes, além da Introdução. São elas: A noção de sistema e os limites da mudança linguística, Produtividade de gênero em PB, Gênero neutro e os limites do sistema e, por fim, Considerações finais. Não é difícil acompanhar a argumentação.

Sendo um ensaio teórico, não há como tecer considerações sobre o modelo experimental.

\subsection{Interpretação}

Deixo algumas perguntas para o A.

"O debate pela inclusão de grupos pertencentes a gêneros em alguma medida marginalizados na esfera social atingiu de cheio a linguagem" (p.2). Essa afirmação constata a motivação social para a proposta de inclusão das novas formas. Ao mesmo tempo expõe um pressuposto que encontramos 


\section{REVISTA DA ABRALIN}

nos manuais de História da Linguística, quando se focalizam os Estoicos: de que língua e realidade objetiva estão naturalmente relacionadas. Este ponto me leva a duas questões.

Em primeiro lugar, a própria terminologia gramatical que herdamos da tradição greco-latina. Segundo Aristóteles, coube a Protágoras (séc. V a.C.) distinguir masculino (gr. arsenikon, lat. masculinum), feminino (gr. thēlukon, lat. femininum), ou nem um, nem outro (gr. oudeteron, lat. neutrum). Com a distinção, Protágoras propunha a correção do gênero (para ele, genos, 'origem', no sentido de que marca um grupo com traços em comum) de alguns nomes gregos, lançando mão para isso do apelo ao significado: é o caso de pēlēx $\left(\pi \eta^{\lambda} \lambda \eta \xi\right)$ 'elmo' , que para ele não deveria ser feminino, mas masculino, porque a guerra é masculina. Por outro lado, reconhecia que também a forma importava, porque costumam ser masculinos os nomes terminados em sigma $<\varsigma>$ ou xi $<\xi>$ (ver Bonazzi, 2020; Matthews, 2019). Gênero não está definido no ensaio. E se ao invés de gênero empregássemos classe de nomes? E se, como no estudo de línguas do Cáucaso, rotulássemos os gêneros por algarismos romanos? (ver Corbett, 1991).

Em segundo lugar está a ampliação do significado do vocábulo gênero fora dos estudos linguísticos. Num dos verbetes da 2007 Wikipedia Selection for schools, do Reino Unido, há uma nota que pode ser aplicada ao português: "In some parts of the social sciences, following a usage shift that began in the 1950s and was well established by the 1980s, gender has been used increasingly to refer to social rather than biological categories, for which the word sex is used". Até que ponto a relação línguarealidade focalizada no ensaio deriva dos novos empregos da palavra gênero?

A seção A noção de sistema e os limites da mudança linguística discute as mudanças introduzidas na língua de modo consciente. Exemplos como amigx, amig@ nascem da escrita. O Curso de Saussure reconheceu essa possibilidade, mas enfatizou o aspecto "teratológico" de mudanças que nascem da escrita. Uma vez que o ensaio retoma a noção de sistema em Saussure, seria interessante adicionar a visão fonocêntrica de Saussure à discussão. Cabe notar, porém, que as mudanças nos exemplos saussureanos afetavam fonemas de palavras isoladas. Sinto falta de mais atenção a propriedades gramaticais lidas pela sintaxe. Em outras palavras: de inovações deliberadas na flexão.

O texto parte da noção de neutralização em Fonologia: "Neutralização, no sentido da Escola de Praga, envolve cancelamento de um contraste, isto é, tem lugar quando duas ou mais entidades opostas deixam de se diferenciar [....] Esse entendimento de neutralização, assim concebido para a fonologia, pode, mutatis mutandis, ser considerado na análise de fenômenos morfofonológicos" (p. 12). Esse entendimento leva a propor que

O uso de caracteres como x ou @ e o uso de e fechando substantivos e adjetivos é de fato uma estratégia de neutralização de gênero, em que se propõe o emprego de uma terceira marca além da masculina e da feminina. A oposição neste caso não é privativa nem equipolente, mas gradual, nos termos da Escola de Praga. (p. 15)

Seria interessante aprofundar o significado de "mutatis mutandis": qual seria, por exemplo, o membro extremo da oposição gradual? (Trubetzkoy (1969: 75). 


\section{REVISTA DA ABRALIN}

\subsection{O texto}

Não há problemas com a redação do texto.

O artigo pode ser publicado, mas gostaria de ver o aprofundamento das questões apontadas.

Referências

BONAZZI, Mauro. 2020. Protagoras In ZALTA, Edward N. (ed.)The Stanford Encyclopedia of Philosophy (Fall 2020 Edition). <https://plato.stanford.edu/archives/fall2020/entries/protagoras/>.

CORBETT, Greville. 1991. Gender. Cambridge: Cambridge University Press.

MATTHEWS, P. H. 2019. What Graeco-Roman Grammar was about. Oxford: Oxford University Press.

SAUSSURE, Ferdinand de. 1916. Curso de Linguística Geral, organizado por Charles Bally e Albert Sechehaye com a colaboração de Albert Riedilinger . Trad. A. Chelini, J. P. Paes e I. Blikstein. São Paulo: Cultrix, 1972.

TRUBETZKOY, N. S. Principles of Phonology. Berkeley / Los Angeles: University of California Press, 1969. 2007 Wikipedia Selection for schools. <https://www.cs.mcgill.ca/ rwest/wikispeedia/wpcd/index.htm> 